\title{
Feeding behavior and agonistic interactions at the feed bunk are associated with hyperketonemia and metritis diagnosis in dairy cattle
}

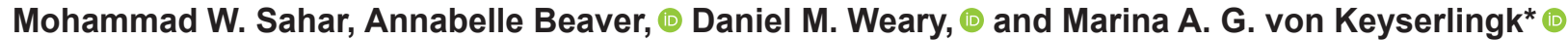 \\ Animal Welfare Program, Faculty of Land and Food Systems, University of British Columbia, Vancouver, British Columbia, Canada, V6T 1 Z4
}

\begin{abstract}
Hyperketonemia and metritis are common in the weeks after calving. This study tested if feeding and agonistic behaviors before calving were associated with the development of hyperketonemia (HYK) and metritis after calving. Holstein cows on 5 commercial farms were monitored for HYK (as identified using a cow-side $\beta$-hydroxybutyrate test) and metritis (using visual and olfactory assessment of vaginal discharge); both tests were conducted twice a week for 2 wk. Based on this assessment, we selected a balanced sample of cows that remained healthy (no signs of illness; $\mathrm{n}=20$ ), cows diagnosed with either HYK $(\mathrm{n}=20)$ or metritis ( $\mathrm{n}=$ $20)$, and cows with both HYK and metritis $(\mathrm{n}=20)$. Video recordings from the 8 wk before calving (scored every 2 wk for 90 min immediately after fresh feed delivery) were used to evaluate feeding behavior and competition at the feed bunk. Feeding behavior before calving was associated with postpartum diagnosis of HYK and metritis. Specifically, cows that spent less time eating had higher odds of HYK and metritis. Odds of remaining healthy (compared with becoming sick with at least 1 condition) increased by 1.3 times for every additional 15 min spent eating. Additionally, cows that were involved in fewer agonistic interactions prepartum were more likely to be diagnosed with both conditions during the postpartum period. Odds of remaining healthy (compared with becoming sick with at least one condition) increased by 1.9 times for every 6 additional interactions. We conclude that prepartum feeding and agonistic behaviors can be used to identify animals at risk of HYK and metritis postpartum.
\end{abstract}

Key words: animal welfare, cow disease, transition period

Received January 9, 2019.

Accepted August 30, 2019.

*Corresponding author: nina@mail.ubc.ca

\section{INTRODUCTION}

Dairy cows are at risk of metabolic and infectious diseases during the transition period (Goff and Horst, 1997; Drackley, 1999; Proudfoot, et al., 2009). Two important transition period diseases are ketosis and metritis (Goff and Horst, 1997; LeBlanc, 2010). Cow-level prevalence of subclinical ketosis was reported to be $43.2 \%$ in a herd in New York (McArt et al., 2012) and ranges from 11 to $49 \%$ in European dairy cattle (Suthar et al., 2013; Berge and Vertenten, 2014). Metritis has been reported to affect 21 to $40 \%$ of cows in European and American dairy herds (Martinez and Thibier, 1984; Zwald et al., 2004; Genís et al., 2018).

Ketosis occurs when body fat reserves are mobilized to meet the elevated energy demands caused by rapid fetal growth, reduced feed intake during the last days of pregnancy (McArt et al., 2012; Vanholder et al., 2015 ), and the onset of milk production in early lactation (Duffield, 2000). Subclinical ketosis occurs when ketone bodies are excessively present in the blood but the cow does not show clinical signs of ketosis (Andersson, 1988). The term "hyperketonemia" (HYK) is used to represent both ketosis and subclinical ketosis (Duffield et al., 2009). Metritis (uterine inflammation) is caused by bacterial infection (LeBlanc et al., 2002) often leading to reduced milk production, decreased reproduction efficiency, and increased culling (LeBlanc, 2008; Overton and Fetrow, 2008; Wittrock et al., 2011). Metritis most commonly occurs shortly after calving, with known risk factors including dystocia, retained placenta, reduced BCS, twins, and stillbirths (Bruun et al., 2002; Dubuc et al., 2010; Vanholder et al., 2015).

Ketosis is traditionally diagnosed by measuring BHB in serum or plasma (Duffield, 2000). Metritis is most often diagnosed via vaginal discharge postpartum, but some cases are likely to go unnoticed (LeBlanc et al., 2002). Early identification of cows at risk for these diseases could reduce the number of sick days experienced by the cow.

Reduced feed intake is associated with ketosis and metritis during the transition period (Marquardt et al., 1977; Huzzey et al., 2007), but individual feed intake 
can be challenging to measure in loose-housed cows on commercial farms. Time spent feeding has also been examined, but the studies yielded conflicting results; some studies found that a decline in time spent feeding prepartum was associated with metritis postpartum (Urton et al., 2005; Huzzey et al., 2007), but others have failed to confirm this association (Neave et al., 2018). Cows that are feeling ill may also be less willing or able to engage in competitive behaviors associated with feeding, so a decline in agonistic behaviors may also help identify cows at risk. To the best of our knowledge, most studies exploring the relationship between feeding or agonistic behaviors and transition disease (Huzzey et al., 2007, metritis; Neave et al., 2018, metritis; González et al., 2008, ketosis) have been conducted in single research-based farms. The aim of this study was to assess if measures of feeding and competitive behavior prepartum were associated with HYK and metritis on commercial farms.

\section{MATERIALS AND METHODS}

This study was conducted in the lower Fraser Valley region of British Columbia during May to December 2017. Herd inclusion criteria were as follows: herd size of 200 or more milking cows housed in free-stall barns with parlor milking, indoor housing of dry cows, dry cows housed separately from lactating cows, and use of an electronic software program for herd management with extractable data. Based on these inclusion criteria, 13 eligible farms were identified using a local claw trimming company. All 13 farms were contacted, and 9 showed interest in participating in the study. Soon after enrollment, 1 farm was dropped due to the configuration of dry pens, which was unsafe for data collection. Data were collected from 8 farms; 3 of which did not have enough cows of interest. The 5 remaining farms had a mean \pm SD herd size of $338 \pm 108$ (median 330; range 250) lactating cows. All animal-related procedures were conducted in compliance with approved animal care protocols from University of British Columbia (ethics approval reference A15-0084).

\section{Subject Enrollment}

A total of 80 multiparous Holstein cows were selected from the 5 farms based on their postpartum health status: (1) healthy cows, (2) cows with metritis, (3) cows with HYK, and (4) cows with both metritis and HYK. To control for the variation between the farms, we chose an equal number of cows in each group, from each farm. On 1 farm, we could only identify 4 cows that were diagnosed with both HYK and metritis. We therefore decided to choose 4 cows in each group (healthy, cows sick with metritis, cows sick with HYK, and cows sick with both metritis and HYK) from each farm, resulting in 20 cows in each group across all farms. When selecting cows with metritis, those with the highest score for vaginal discharge (score 4 assigned at least once; see Sheldon et al., 2006) and with lowest level of BHB were selected. We used this approach to maximize the chance that any effect was due to metritis. For cows with HYK, we selected those with the highest BHB and a 0 score for metritis to maximize the chance that any effect was due to HYK.

\section{Data Collection}

All cows that were expected to calve between July 21 and December 1, 2017, in the selected farms were enrolled in the study. Video cameras (GoPro HERO4 Silver, GoPro Inc., San Mateo, CA) were used to record feeding and agonistic interactions for the first $90 \mathrm{~min}$ after fresh feed delivery at the feed bunk. The cameras were fixed $5 \mathrm{~m}$ above the pen. Videos were recorded once every other week for 8 wk. Cows were marked with symbols using fluorescent animal marker (Tell Tail Aerosol, FIL Industries, Tauranga, New Zealand).

Latency to enter the feed bunk, time spent at the feed bunk, time spent in the cow feed alley while waiting to access feed, and the number of agonistic interactions were recorded. All measures were recorded by trained observers who were blind to the disease status of the cow. The observation period started when the feed truck passed the pen and excluded interruptions when cows were locked in headlocks, when the image was obstructed (e.g., the feed truck was temporarily parked in the cow feed alley blocking the view), or the farmer was interacting with the focal cow or the animals nearby, potentially affecting the cows' behavior. Any time missed due to these interruptions was substituted with video immediately following the $90 \mathrm{~min}$; interruptions occurred in $23 \%$ of the videos. The minimum interruption recorded was $11 \mathrm{~s}$ and the maximum was $14 \mathrm{~min}$. Latency was recorded from the time the observation started until the subject appeared at the feed bunk. Cows were continuously monitored for 90 min after fresh feed delivery. Time spent feeding was recorded each time the cow entered the feed bunk during this time (i.e., from the moment the cow's ears crossed the headlocks to the moment when the ears returned to the cow feed alley side of the headlocks). Time spent feeding was subtracted from the time the subject was present in the cow feed alley but not feeding to calculate the time waiting to access the feed bunk. Agonistic interactions included actor behaviors (subject displaced/replaced another cow from the feed bunk using her head, shoulders, or flank) and reactor 
Table 1. Ethogram of transition period cow behaviors measured in the prepartum period

\begin{tabular}{|c|c|}
\hline Behavior & Description \\
\hline \multicolumn{2}{|l|}{ Feeding } \\
\hline Latency to reach the feed bunk & $\begin{array}{l}\text { Beginning from the time the fresh feed was delivered and the feed truck fully passed the pen until } \\
\text { the time the subject appeared and her ears crossed the headlocks toward the feed bunk }\end{array}$ \\
\hline Time present in the cow feed alley & $\begin{array}{l}\text { Beginning from the time the subject entered the cow feed alley with all } 4 \text { feet until the time all } 4 \\
\text { feet were out of the cow feed alley }\end{array}$ \\
\hline $\begin{array}{l}\text { Time present in the cow feed alley } \\
\text { but not feeding }\end{array}$ & Calculated as the total time spent in the cow feed alley minus the time spent eating \\
\hline \multicolumn{2}{|l|}{ Agonistic } \\
\hline Actor behavior & $\begin{array}{l}\text { Using her head, shoulders, or flank, the subject displaces another cow from the feed bunk (with or } \\
\text { without replacement) }\end{array}$ \\
\hline
\end{tabular}

behaviors (subject was displaced/replaced by another cow from feed bunk using the head, shoulders, or flank).

Health (HYK and metritis) was assessed twice a week for 2 wk after calving. Blood samples were taken from the coccygeal vessels to measure BHB in whole blood using the Precision Xtra $\beta$-ketone handheld device (Abbott Diabetes Care, Mississauga, ON, Canada; Iwersen et al., 2009). Before venipuncture, the sample collection spot was cleaned using an alcohol swab. The sample was then collected in red-top vacuum tubes $(10.0-\mathrm{mL}$ BD Vacutainer glass serum tube, silicone-coated; Becton Dickinson and Co., Franklin Lakes, NJ). The BHB tests were conducted within an hour of sample collection. The threshold for subclinical ketosis was set at $\geq 1.2 \mathrm{mmol} / \mathrm{L}$ (Duffield et al., 1998).

Vaginal discharge was used to assess metritis. The discharge was collected by means of palpation sleeves and a lubricant solution after cleaning the vulva with fresh water and soap and drying it with a paper towel as described in Huzzey et al. (2007). The discharge was then assessed by visual and olfactory judgments and scored as $1=$ clear or slightly bloody or small flecks of pus, no foul smell; $2=<50 \%$ pus flecks, with foul smell; $3=>50 \%$ pus flecks and foul smell; or $4=$ foul smell and red/brown watery discharge (Sheldon et al., 2006). Cows were considered metritic if vaginal discharge scored 4 on at least 1 occasion.

\section{Statistical Analysis}

Statistical analyses were performed using SAS (version 9.4; SAS Institute Inc., Cary, NC), and figures were generated using GraphPad Prism (Version 7; GraphPad Inc., La Jolla, CA). Using scores from 6 videos watched by 2 observers, interobserver reliability was calculated using Pearson correlations.

Descriptive Analysis. All prepartum behaviors thought to predict or influence postpartum disease status were considered for model inclusion. These variables are shown in Table 1. The distribution of each variable was first investigated using PROC Univariate. The patterns for eating and agonistic behaviors were explored graphically according to postpartum disease status and in relation to calving date. The measurement closest to calving for each animal was viewed to have the highest predictive ability for postpartum disease status because the greatest variability between the disease categories occurred when the animals were closest to calving. We thus included only this last observation in our final model. The associations between 2 continuous variables were assessed using Pearson correlation; if 2 variables were correlated at $r \geq 0.7$ we retained only the variable that was more strongly related to the outcome in the univariable analysis.

Model Development. As a first step in model development, univariable, mixed logistic regression models were run using PROC Glimmix. Because of the small number of herds in the study $(\mathrm{n}=5)$, herd was included as a fixed effect in all models. Each model included an additional fixed explanatory variable. The outcome variable in all models was disease status (with levels for "healthy," "sick with either HYK or metritis," and "sick with both conditions"). Because the outcome variable had 3 levels, ordinal logistic regression models were run using the cumulative logit as a link function.

A final mixed ordinal logistic regression model was then developed including variables reaching the $P<$ 0.10 threshold level in their respective univariable 
models. Herd was again included as a fixed effect. The model underwent a manual backward stepwise selection procedure, with the final model containing only variables meeting a $P<0.05$ threshold. Model fit was assessed using the Hosmer and Lemeshow goodness-of-fit test (by means of the "lackfit" coding statement). The model had no lack of fit $(P=0.46)$. We also visualized each predictor against the logit of the outcome (linear predictor) to confirm linear relationships.

To illustrate the results from our ordinal logistic regression model, predicted probabilities of disease under different scenarios were calculated using the following formulae:

$$
\begin{gathered}
p(\text { healthy })=\frac{e^{\left(\alpha_{1}+\beta X\right)}}{1+e^{\left(\alpha_{1}+\beta X\right)}}, \\
p(\text { sick with } 1 \text { condition })=\frac{e^{\left(\alpha_{2}+\beta X\right)}}{1+e^{\left(\alpha_{2}+\beta X\right)}}-p(\text { healthy }), \\
p(\text { sick with } 2 \text { conditions })=\frac{1}{1+e^{\left(\alpha_{2}+\beta X\right)}},
\end{gathered}
$$

where $p$ represents the probability of occurrence, $\alpha_{1}$ represents the intercept for healthy animals, $\alpha_{2}$ represents the cumulated intercept for animals sick with 1 and 2 conditions, $\beta$ represents the slope associated with eating time, and $X$ represents the value of interest for eating time.

\section{RESULTS}

\section{Interobserver Reliability}

Interobserver $(\mathrm{r}=0.99$ and $\mathrm{r}=0.97)$ and intra-observer $(r>0.99$ and $r>0.99)$ reliability were excellent for both time spent feeding and for total number of agonistic interactions.

\section{Univariable Analyses}

Feeding Behaviors. The average time spent eating during the 90 min after fresh feed delivery decreased as animals approached calving (mean $\pm \mathrm{SD}$ of $59 \pm 23 \mathrm{~min}$ at $>6$ wk from calving versus $48 \pm 26 \mathrm{~min}$ in the week before calving). This decrease was most pronounced for cows that later became sick with both HYK and metritis (see Figure 1; Supplemental Figure S1 shows the time spent feeding at the farm level: https://doi.org/ 10.3168/jds.2019-16278). According to the univariable model, cows that remained healthy after calving tended to spend more time in the cow feed alley compared

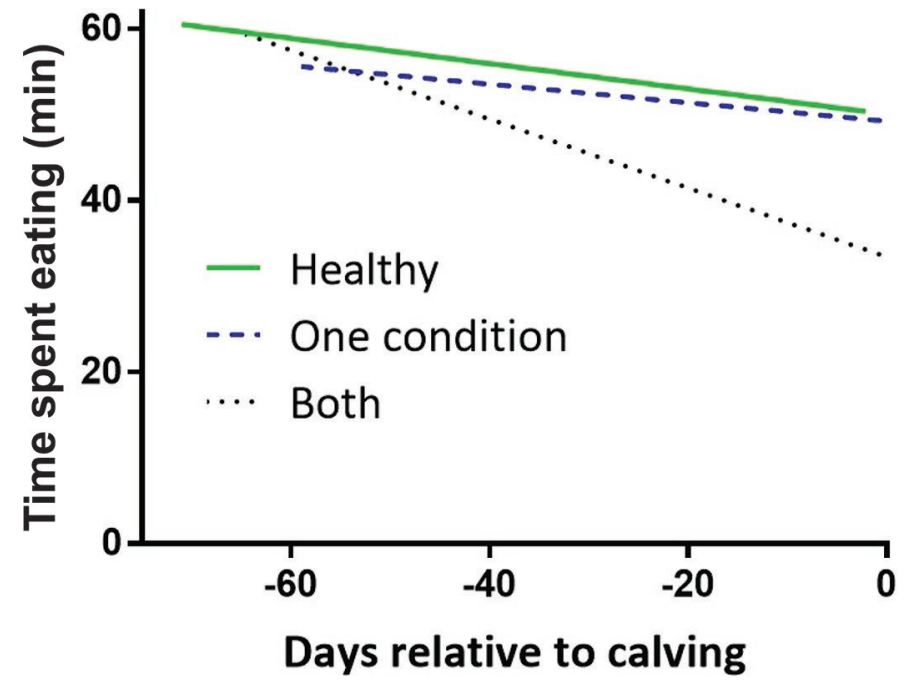

Figure 1. The relationship between time spent eating (in the 90 min after fresh-feed delivery) during the prepartum period and disease status postpartum. The data are summarized by means of best-fit lines for 3 groups: cows that remained healthy postpartum $(n=20)$, those that became sick with 1 condition (either HYK or metritis; $\mathrm{n}=40$ ), and those that became sick with both HYK and metritis $(\mathrm{n}=20)$. Time spent eating (in min) is shown on the $y$-axis and days relative to calving on the $x$-axis, with d 0 representing parturition. HYK = hyperketonemia.

with the cows that were diagnosed with both metritis and HYK (Table 2; $P=0.08$ ). Additionally, cows that remained healthy spent more time eating than did cows later diagnosed with both conditions $(P=0.03)$. Latency to eat during the prepartum period did not relate to disease postpartum $(P>0.20)$. In the $90 \mathrm{~min}$ following fresh feed delivery, cows spent between 0 and 88 min eating (median $=50 \mathrm{~min}$ ), with cows at the 25 th percentile spending almost 30 of the 90 min eating. For every additional 15 min that an animal spent eating during the observation period, she had 1.3 times higher odds of remaining healthy compared with becoming sick with at least 1 condition after calving.

Agonistic Behaviors. Cows that remained healthy postpartum were involved in more agonistic interactions (including both actor and reactor behaviors) compared with cows that developed both HYK and metritis $(P=$ 0.02 ; Figure 2). The observed values for this variable ranged from 0 to 18 interactions, with 2 and 8 interactions representing the 25 th and 75 th percentiles, respectively (interquartile range $=6$ interactions). To reflect a biologically relevant increase, we calculated the odds ratio for the model based upon a 6 -unit increase in the number of agonistic interactions; for every 6 additional interactions, cows had 1.9 times higher odds of remaining healthy postpartum compared with becoming sick with 1 or 2 conditions (Table 2). In addition, when actor and reactor behaviors were looked at separately, 


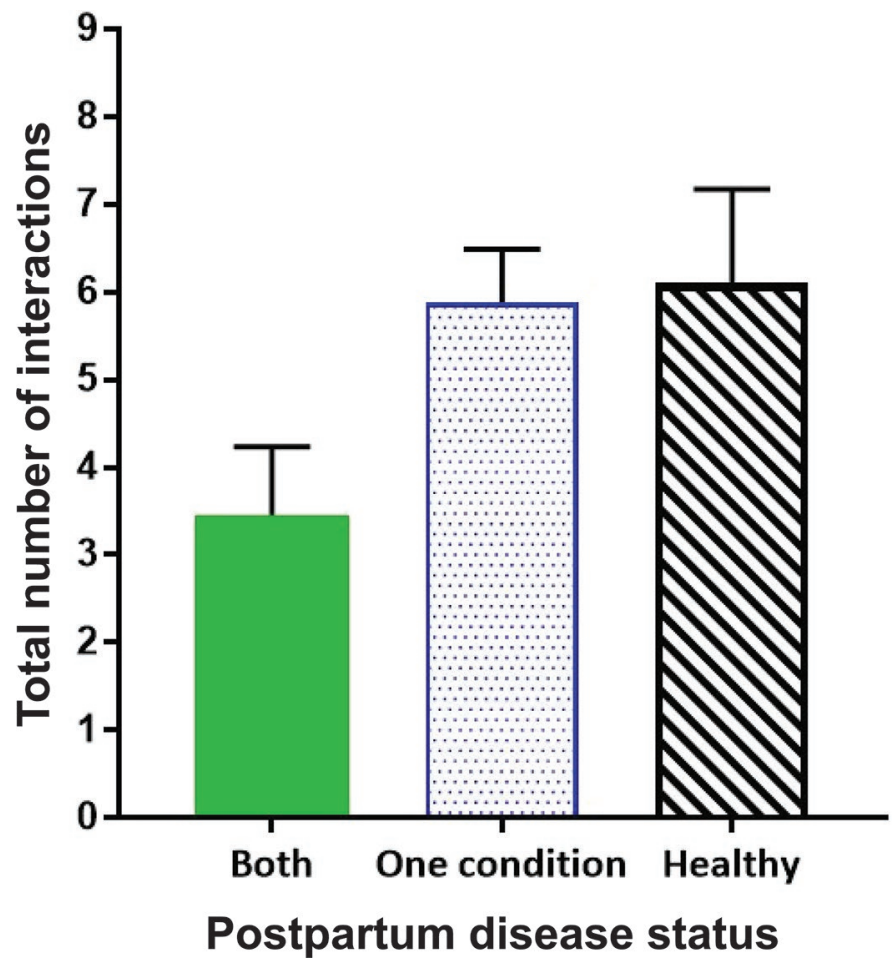

Figure 2. Total agonistic interactions versus postpartum disease status. This figure shows the average number of prepartum interactions (in the $90 \mathrm{~min}$ following fresh feed delivery) on the $y$-axis and postpartum disease status on the $x$-axis. The categories both (i.e., HYK and metritis; $\mathrm{n}=20$ ), 1 condition (i.e., HYK or metritis; $\mathrm{n}=$ $40)$, and healthy $(\mathrm{n}=20)$ are shown. Error bars represent 1 SEM. HYK = hyperketonemia.

cows with 2 conditions performed fewer actor behaviors compared with cows that remained healthy during the postpartum period $(P=0.04)$. In contrast, reactor behaviors were similar between the groups. Figure 3 shows the relationship between postpartum disease and actor and reactor behaviors, illustrating the marked de-

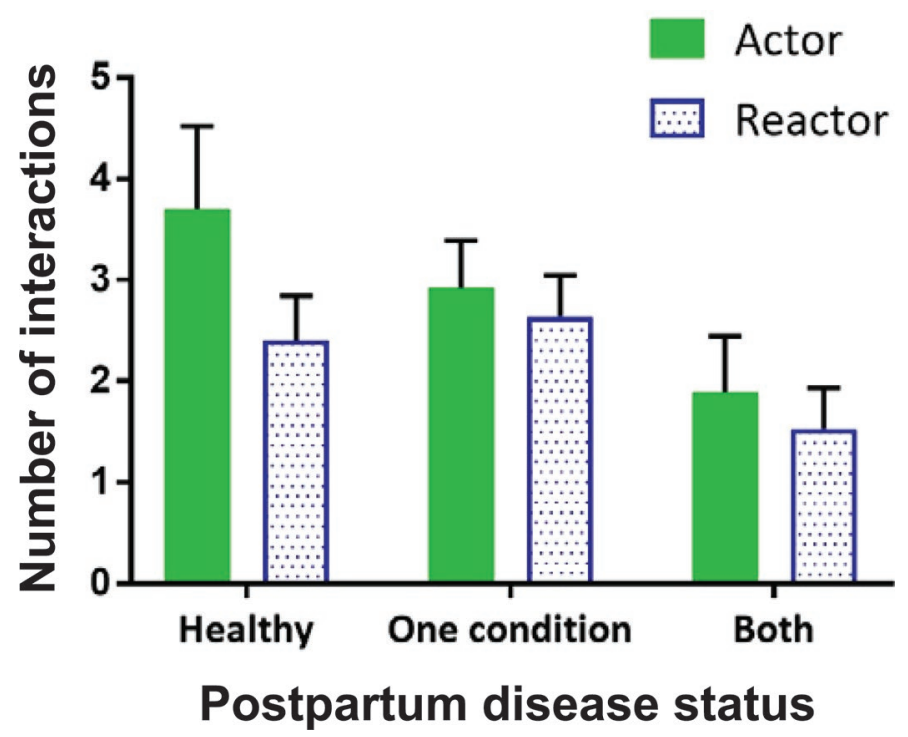

Figure 3. Actor and reactor behaviors versus postpartum disease status. The average number of prepartum actor and reactor behaviors (in the $90 \mathrm{~min}$ following fresh feed delivery) is shown on the $y$-axis and postpartum disease status is on the $x$-axis. The categories both (i.e., HYK and metritis; $\mathrm{n}=20$ ), 1 condition (i.e., HYK or metritis; $\mathrm{n}$ $=40)$, and healthy $(\mathrm{n}=20)$ are shown. Error bars represent 1 SEM. $\mathrm{HYK}=$ hyperketonemia.

crease in actor behaviors for cows diagnosed with both conditions postpartum.

\section{Final Model}

Actor behaviors and total agonistic interactions were highly correlated $(\mathrm{r}=0.85)$, so both could not be entered simultaneously into the multivariable model. We used the total number of interactions because this variable was a more comprehensive measure of agonistic behavior and was more strongly related to the outcome. After the application of manual backward stepwise removal,

Table 2. Results from the univariable analysis, including slope $(\beta)$, and the associated SE, $P$-values (for type III sum of squares), and odds ratio (OR) and $95 \% \mathrm{CI}^{1}$

\begin{tabular}{lrccc}
\hline Behavior & Slope & SE & $P$-value & OR (95\% CI) \\
\hline Feeding behaviors & & & & \\
Time spent feeding $^{2}$ & 0.293 & 0.135 & 0.03 & $1.34(1.03-1.75)$ \\
Latency $^{2}$ & -0.169 & 0.133 & 0.20 & $0.84(0.65-1.10)$ \\
Time present $^{2}$ & 0.216 & 0.122 & 0.08 & $1.24(0.98-1.58)$ \\
Time present while waiting to feed $^{2}$ & -0.187 & 0.306 & 0.54 & $0.83(0.46-1.51)$ \\
Agonistic behaviors $^{3}$ & & & & \\
Total interactions $^{3}$ & 0.831 & 0.355 & 0.02 & $2.30(1.15-4.60)$ \\
Actors $^{3}$ & 0.900 & 0.443 & 0.04 & $2.45(1.03-5.84)$ \\
Reactors $^{3}$ & 0.674 & 0.614 & 0.27 & $1.96(0.59-6.53)$ \\
\hline
\end{tabular}

${ }^{1}$ Postpartum disease status served as the outcome variable in each model, with levels of healthy $(\mathrm{n}=20)$, sick with 1 condition $(\mathrm{n}=40)$, and sick with both conditions $(\mathrm{n}=20)$. The probabilities modeled are cumulated over the lower ordered values, with healthy $=1$, sick with 1 condition $=2$, and sick with both conditions $=3$. ${ }^{2}$ Slope, SE, OR, and 95\% CI are calculated based upon 15-min increments.

${ }^{3}$ Slope, SE, OR, and $95 \%$ CI are calculated based upon 6 interactions. 
time spent eating was the only behavior remaining in the model; therefore, the final model was identical to the univariable model reported above.

\section{DISCUSSION}

\section{Feeding Behaviors}

Huzzey et al. (2007) found that cows that went on to develop metritis had reduced feed intake in the weeks before calving. Similarly, González et al. (2008) reported reduced feed intake (approximately $10 \mathrm{~kg}$ of fresh matter per day) in the days before diagnosis with HYK. Previous results (Huzzey et al., 2007, metritis in transition period cows; Neave et al., 2018, metritis during the postpartum period; González et al., 2008, ketosis during the prediagnosis period) were from single farms designated for research purposes. The current study provides a constructive extension by showing similar results for cows housed on 5 different commercial farms.

The feeding behavior differences between healthy and sick cows reported in previous studies are based on fullday assessments; our study only considered the first 90 min after fresh feed delivery. This period was selected based on DeVries et al. (2004), who showed that competitive interactions and feed bunk attendance peaked during the $90 \mathrm{~min}$ after fresh feed delivery. The results of the current study suggest that this shortened period of observation is still useful for identifying animals at risk and thus illustrates a more efficient approach to monitoring. From a practicality standpoint, farmers are unlikely to observe each cow for 90 min to record feeding and agonistic behaviors; some type of automatic data collection (e.g., automatic feed bins to collect the data, computer vision approaches) is likely necessary before these measures could be implemented on commercial farms.

Time spent eating during 90 min after fresh feed delivery prepartum ranged from 0 to $88 \mathrm{~min}$. Our model indicates that a cow spending 88 of the 90 min eating would have an $87 \%$ chance of avoiding a double diagnosis of HYK and metritis postpartum. In contrast, animals that did not eat during the observation period would have an $89 \%$ chance of becoming sick with at least 1 condition following calving. Animals spending $\leq 30$ min eating (the bottom 25th percentile of our data) would still have a $\geq 82 \%$ chance of becoming sick.

Interestingly, healthy cows in our study tended to spend more time in the cow feed alley (during the prepartum period) than did cows diagnosed with both HYK and metritis. Although this finding was only apparent in the univariable analysis, time present in the cow feed alley may represent a more readily measurable proxy for feeding behavior, and its association with disease prevalence postpartum should be investigated further.

\section{Agonistic Behaviors}

Cows diagnosed with 2 conditions (HYK and metritis) during the postpartum period engaged in fewer agonistic interactions prepartum. This finding is consistent with the observation that dairy cows seek social isolation from the herd when they are sick (Proudfoot et al., 2014). Although this variable did not add predictive ability to our model once time spent feeding was included (likely because agonistic behaviors can only happen when the animal is eating), the odds of remaining healthy (compared with becoming sick with at least 1 condition) almost doubled for every 6 -unit increase in prepartum interactions.

In the univariable analysis stage, we examined actor (when the subject displaces another cow from the feed bunk) and reactor (when the subject is displaced by another cow from the feed bunk) behaviors separately. Cows that had fewer successful occasions of displacing other cows from the feed bunk prepartum tended to be less likely to remain healthy (see Table 2 and Figure 3), but the frequency of reactor behaviors was not associated with disease outcome.

Our results are in agreement with earlier work on agonistic behavior and diseases in dairy cows. Goldhawk et al. (2009) reported fewer displacements for cows that were later diagnosed with ketosis. Likewise, cows that developed metritis in weeks after calving engaged in fewer agonistic interactions before calving (Huzzey et al., 2007). In contrast, Neave et al. (2018) were not able to confirm this association. However, this latter study only recorded replacements (a cow replaces another cow from the feed bunk), rather than displacements (a cow displaces another cow from the feed bunk but does not take her spot).

\section{Limitations and Future Directions}

We caution the reader that the results of the ordinal logistic regression model used in the present study should not be interpreted as a binary logistic model. Although healthy animals and animals sick with 1 disease had similar average numbers of total interactions and feeding times, we elected to keep these groups separate rather than grouping healthy and sick animals together. We hypothesize that biological differences are present between healthy animals and those sick with 1 disease; therefore, we could not justify grouping them for analysis. The odds ratios presented throughout reflect a cumulation of animals sick with 1 or 2 conditions compared with healthy animals; the reciprocals of 
the reported odds ratios are, by definition, equivalent to odds ratios for double-diagnosed animals compared with the cumulation of both other groups. We have also incorporated some scenario probabilities to provide comparisons between animals sick with 2 diseases versus the other 2 groups.

A further limitation of the present study is that cattle were observed only once every second week. Thus, the final observation for each animal ranged from 14 to $1 \mathrm{~d}$ before calving. Feeding behavior changes during this period (Goldhawk et al., 2009), and these changes may have reduced our ability to detect other differences before calving.

A critical window may exist before calving during which time spent eating and the number of agonistic interactions decline at a more rapid rate. Further research is needed to pinpoint the onset of this decline. Additionally, it remains to be determined whether the participation in lower numbers of agonistic interactions at the feed bunk somehow contributes to disease (e.g., through a resulting decrease in feed intake), or if the onset of disease causes the reduction in agonistic interactions and time spent eating.

\section{CONCLUSIONS}

Cows that spend less time eating during the first 90 min after fresh feed delivery in the prepartum period are at increased risk of developing HYK and metritis in the postpartum period. Additionally, univariable models revealed that cows spending more time in the cow feed alley had higher odds of remaining healthy postpartum. Cows at risk of HYK and metritis were more often displaced from the feed bunk before becoming sick. We conclude that prepartum feeding and agonistic behaviors can be useful in identifying animals at risk of postpartum HYK and metritis.

\section{ACKNOWLEDGMENTS}

Our thanks go to Hanna Eriksson, Ruan Daros, Paige McDonald, and Samantha Jung from the Animal Welfare Program for helping in data collection. Our thanks also go to the farmers for providing the environment for smooth data collection in their respective farms. This project was funded in part by British Columbia Dairy Association DIREC and Investment Agriculture Foundation (grant no. A0850). General funding for the Animal Welfare Program is provided to MvK and DMW by Canada's Natural Sciences and Engineering Research Council (NSERC) via the Industrial Research Chair Program with industry contributions from the Dairy Farmers of Canada (Ottawa, ON, Canada),
British Columbia Dairy Association (Burnaby, BC Canada), Westgen Endowment Fund (Milner, BC, Canada), Intervet Canada Corporation (Kirkland, QC, Canada), Zoetis (Kirkland, QC, Canada), Novus International Inc. (Oakville, ON, Canada), BC Cattle Industry Development Fund (Kamloops, BC, Canada), Alberta Milk (Edmonton, AB, Canada), Valacta (St. Anne-de-Bellevue, QC, Canada), and CanWest DHI (Guelph, ON, Canada).

\section{REFERENCES}

Andersson, L. 1988. Subclinical ketosis in dairy cows. Vet. Clin. North Am. Food Anim. Pract. 4:233-251.

Berge, A. C., and G. Vertenten. 2014. A field study to determine the prevalence, dairy herd management systems, and fresh cow clinical conditions associated with ketosis in western European dairy herds. J. Dairy Sci. 97:2145-2154.

Bruun, J., A. K. Ersbøll, and L. Alban. 2002. Risk factors for metritis in Danish dairy cows. Prev. Vet. Med. 54:179-190.

DeVries, T. J., M. A. von Keyserlingk, and D. M. Weary. 2004. Effect of feeding space on the inter-cow distance, aggression, and feeding behavior of free-stall housed lactating dairy cows. J. Dairy Sci. 87:1432-1438.

Drackley, J. K. 1999. Biology of dairy cows during the transition period: The final frontier? J. Dairy Sci. 82:2259-2273.

Dubuc, J., T. F. Duffield, K. E. Leslie, J. S. Walton, and S. J. LeBlanc. 2010. Risk factors for postpartum uterine diseases in dairy cows. J. Dairy Sci. 93:5764-5771.

Duffield, T., 2000. Subclinical ketosis in lactating dairy cattle. Vet. Clin. North Am. Food Anim. Pract. 16:231-253.

Duffield, T. F., K. D. Lissemore, B. W. McBride, and K. E. Leslie. 2009. Impact of hyperketonemia in early lactation dairy cows on health and production. J. Dairy Sci. 92:571-580.

Duffield, T. F., D. Sandals, K. E. Leslie, K. Lissemore, B. W. McBride, J. H. Lumsden, P. Dick, and R. Bagg. 1998. Efficacy of monensin for the prevention of subclinical ketosis in lactating dairy cows. J. Dairy Sci. 81:2866-2873

Genís, S., R. L. Cerri, À. Bach, B. F. Silper, M. Baylao, J. DenisRobichaud, and A. Arís. 2018. Pre-calving intravaginal administration of lactic acid bacteria reduces metritis prevalence and regulates blood neutrophil gene expression after calving in dairy cattle. Front. Vet. Sci. 5:135.

Goff, J. P., and R. L. Horst. 1997. Physiological changes at parturition and their relationship to metabolic disorders. J. Dairy Sci. 80:1260-1268.

Goldhawk, C., N. Chapinal, D. M. Veira, D. M. Weary, and M. A. von Keyserlingk. 2009. Prepartum feeding behavior is an early indicator of subclinical ketosis. J. Dairy Sci. 92:4971-4977.

González, L. A., B. J. Tolkamp, M. P. Coffey, A. Ferret, and I. Kyriazakis. 2008. Changes in feeding behavior as possible indicators for the automatic monitoring of health disorders in dairy cows. J. Dairy Sci. 91:1017-1028.

Huzzey, J. M., D. M. Veira, D. M. Weary, and M. A. G. von Keyserlingk. 2007. Prepartum behavior and dry matter intake identify dairy cows at risk for metritis. J. Dairy Sci. 90:3220-3233.

Iwersen, M., U. Falkenberg, R. Voigtsberger, D. Forderung, and W. Heuwieser. 2009. Evaluation of an electronic cowside test to detect subclinical ketosis in dairy cows. J. Dairy Sci. 92:2618-2624.

LeBlanc, S. 2010. Monitoring metabolic health of dairy cattle in the transition period. J. Reprod. Dev. 56:S29-S35.

LeBlanc, S. J. 2008. Postpartum uterine disease and dairy herd reproductive performance: A review. Vet. J. 176:102-114.

LeBlanc, S. J., T. F. Duffield, K. E. Leslie, K. G. Bateman, G. P Keefe, J. S. Walton, and W. H. Johnson. 2002. Defining and diagnosing postpartum clinical endometritis and its impact on reproductive performance in dairy cows. J. Dairy Sci. 85:2223-2236. 
Marquardt, J. P., R. L. Horst, and N. A. Jorgensen. 1977. Effect of parity on dry matter intake at parturition in dairy cattle. J. Dairy Sci. 60:929-934.

Martinez, J., and M. Thibier. 1984. Reproductive disorders in dairy cattle: I. Respective influence of herds, seasons, milk yield and parity. Theriogenology 21:569-581.

McArt, J. A. A., D. V. Nydam, and G. R. Oetzel. 2012. Epidemiology of subclinical ketosis in early lactation dairy cattle. J. Dairy Sci. 95:5056-5066.

Neave, H. W., J. Lomb, D. M. Weary, S. J. LeBlanc, J. M. Huzzey, and M. A. G. von Keyserlingk. 2018. Behavioral changes before metritis diagnosis in dairy cows. J. Dairy Sci. 101:4388-4399.

Overton, M., and J. Fetrow. 2008. Economics of postpartum uterine health. Pages 39-44 in Proc. Dairy Cattle Reproduction Council. Dairy Cattle Reproduction Council, Omaha, NE.

Proudfoot, K. L., M. B. Jensen, D. M. Weary, and M. A. G. von Keyserlingk. 2014. Dairy cows seek isolation at calving and when ill. J. Dairy Sci. 97:2731-2739.

Proudfoot, K. L., D. M. Veira, D. M. Weary, and M. A. G. von Keyserlingk. 2009. Competition at the feed bunk changes the feeding, standing, and social behavior of transition dairy cows. J. Dairy Sci. 92:3116-3123.

Sheldon, I. M., G. S. Lewis, S. LeBlanc, and R. O. Gilbert. 2006. Defining postpartum uterine disease in cattle. Theriogenology 65:1516-1530.

Suthar, V. S., J. Canelas-Raposo, A. Deniz, and W. Heuwieser. 2013. Prevalence of subclinical ketosis and relationships with postpartum diseases in European dairy cows. J. Dairy Sci. 96:2925-2938.
Urton, G., M. A. von Keyserlingk, and D. M. Weary. 2005. Feeding behavior identifies dairy cows at risk for metritis. J. Dairy Sci. 88:2843-2849.

Vanholder, T., J. Papen, R. Bemers, G. Vertenten, and A. C. B. Berge. 2015. Risk factors for subclinical and clinical ketosis and association with production parameters in dairy cows in the Netherlands. J. Dairy Sci. 98:880-888.

Wittrock, J. M., K. L. Proudfoot, D. M. Weary, and M. A. G. von Keyserlingk. 2011. Short communication: Metritis affects milk production and cull rate of Holstein multiparous and primiparous dairy cows differently. J. Dairy Sci. 94:2408-2412.

Zwald, N. R., K. A. Weigel, Y. M. Chang, R. D. Welper, and J. S. Clay. 2004. Genetic selection for health traits using producerrecorded data. I. Incidence rates, heritability estimates, and sire breeding values. J. Dairy Sci. 87:4287-4294.

\section{ORCIDS}

Annabelle Beaver () https://orcid.org/0000-0002-2953-9574

Daniel M. Weary @ \ttps://orcid.org/0000-0002-0917-3982

Marina A. G. von Keyserlingk (1) https://orcid.org/0000-0002-1427 $-3152$ 